\title{
A type II-collagen derived peptide and its nitrated form as new markers of inflammation and cartilage degradation in equine osteochondral lesions
}

\author{
M. Gangl ${ }^{\text {a, } 1}$, D. Serteyn ${ }^{\text {a,c,d }}$, J.-Ph. Lejeune ${ }^{\text {d }}$, N. Schneider ${ }^{\text {d }}$, S. Grulke ${ }^{\text {a }}$, F. Peters ${ }^{\text {a }}$, T. Vila ${ }^{\text {e }}$, G. Deby-Dupont \\ ${ }^{\mathrm{c}}$, M. Deberg ${ }^{\mathrm{b}}$, Y. Henrotin ${ }^{\mathrm{b}, \mathrm{c}}$ \\ ${ }^{a}$ Department of Clinical Sciences, Large Animal Surgery, Faculty of Veterinary Medicine, University of Liège, Sart Tilman B41, B-4000 \\ Liège, Belgium \\ ${ }^{\mathrm{b}}$ Bone and Cartilage Research Unit, University of Liège, Belgium \\ ${ }^{\mathrm{c}}$ Center for Oxygen Research and Development, University of Liège, Belgium \\ ${ }^{\mathrm{d}}$ European Horse Center, Mont-le-Soie, Vielsalm, Belgium \\ ${ }^{\text {e } C l i n i q u e ~ V e ́ t e ́ r i n a i r e ~ E q u i n e, ~ C h a n t i l l y, ~ F r a n c e ~}$
}

\begin{abstract}
Markers of cartilage breakdown enable studying the degradation of cartilage matrix in equine joint pathologies. This study was designed to determine the levels of Coll2-1, a peptide of the triple helix of type II collagen, and Coll2- $1 \mathrm{NO}_{2}$, its nitrated form in the plasma of healthy horses (controls; $n=37$ ) and horses suffering from osteochondrosis $(n=34)$. Clinical and arthroscopic scores were attributed reflecting the severity of lesions and were related to the plasma levels of Coll2-1 and Coll2-1 $\mathrm{NO}_{2}$. The median of Coll2-1 was significantly higher in the control group, whereas the mean of Coll2- $1 \mathrm{NO}_{2}$ showed significant elevation in the pathological group. However, the measurement means of scoring classes did not vary significantly. The markers were able to differentiate the group of horses suffering from osteochondrosis from the group of healthy horses. The elevation of Coll2- $1 \mathrm{NO}_{2}$ in the pathological group indicates an inflammation, mediated through reactive oxygen species and/or increased myeloperoxidase activity.
\end{abstract}

\section{Introduction}

Lameness is the most important cause of wastage in horses performing athletic activities. Among the causes of lameness, joint disease is very frequently diagnosed (Todhunter and Lust, 1990). In growing horses articular osteochondrosis is a major joint pathology with high prevalence and important economic impact. It begins as an abnormal chondrocyte development and maturation, leading to altered endochondral ossification with further damage to the cartilage, resulting in osteochondral lesions or fragmentation and incongruency of the articular cartilage, which might ultimately develop into degenerative arthritis (Jeffcott, 1991; Jeffcott and Henson, 1998). The pathogenesis of equine osteochondrosis and osteochondral fragmentation remains to be elucidated, although several factors such as genetic predisposition, endocrine dysfunction, nutritional imbalance and deficiencies, focally deficient blood supply, exercise and trauma have been proposed (Douglas, 2003).

Several research groups have investigated the extracellular matrix of normal growth cartilage (Henson et al., 1996) and compared it to cartilage in osteochondrotic lesions in order to detect molecular changes at this level (Jeffcott and Henson, 1998). Loss of glycosaminoglycans (Lillich et al., 1997) and decrease of proteoglycan production(Van den Hoogen et al., 1999) in osteochondrotic cartilage have been detected. Alterations of the other major constituent of extracellular cartilage matrix, type II-collagen, have also been noted. In studies with foals fed a copper-deficient diet, decrease in total type II-collagen content (Bridges and Harris, 1988) and reduced levels of type II-collagen cross-links (Hurtig et al., 1993) were found in osteochondrotic lesions.

In human medicine, osteoarthritis and rheumatoid arthritis are common pathologies, both of which are characterised by articular cartilage breakdown. Biochemical and immunological markers of cartilage turnover have been identified and quantified in biological fluids (Lohmander, 1997; Poole, 2003). Type II-collagen is specific for cartilage and is the most abundant protein in the extracellular matrix, and measurements of its

\footnotetext{
${ }^{1}$ Département Hippique, Ecole Nationale Vétérinaire de Lyon, 1, avenue Bourgelat, B.P. 83 F-69280 Marcy l'Etoile, France.
} 
fragments can be taken as a marker of cartilage degeneration. Antibodies that recognize neoepitopes generated through cleavage of the type II-collagen molecule by collagenases have been obtained and used to develop immunological methods to measure type II-collagen degradation in tissues and biological fluids (Garnero et al., 2000; Poole, 2003; Henrotin et al., 2004; Deberg et al., 2005). Some of these antibodies have been adapted to the equine species and applied in situ to the measurement of type II-collagen breakdown in osteoarthritis (Billingshurst et al., 2001) and in serum to measure the influence of exercise (Billingshurst et al., 2003) as well as to differentiate cartilage degeneration due to strenuous exercise from that due to osteoarthritic pathology (Frisbie et al., 2002). Until now few studies have used this new technology to investigate type II-collagen breakdown in equine osteochondrosis. Laverty et al. (2002) used an ELISA method to detect the so-called COL2-3/4C $\mathrm{C}_{\text {short }}$ epitope, which is generated on cleavage of the triple helix. They found an increase of this epitope in cartilage explants from osteochondral lesions from the femoro-patellar joint of immature horses. Billingshurst et al. (2004) evaluated the serum concentration of markers of skeletal metabolism and tried to correlate them with the results of radiography as indicators of severity of osteochondrosis in foals. At 5 months of age, the biomarkers of collagen degeneration correlated positively with the severity of macroscopic osteochondral lesion, whereas at 11 months a negative correlation with the severity of lesions and one of the biomarkers was detected.

Other research on the pathophysiological events of cartilage breakdown concerns the role of mediators such as proteolytic enzymes, cytokines and reactive oxygen species (ROS) (Caron, 2003). ROS have been widely investigated for their role in the pathogenesis of human osteoarthritis (Stichtenoth and Frôlich, 1998; Henrotin et al., 2003; Schiller et al., 2003), but their role in equine joint pathology has been the subject of very few studies (Dimock et al., 2000; Von Rechenberg et al., 2000). Dimock et al. (2000) were the first to demonstrate an increased protein carbonyl content of synovial fluid from equine joints with osteochondral fragmentation, suggesting an in situ production of ROS.

In this study, we have used two competitive immunoassays specific for a breakdown product of human type IIcollagen and its nitrated form. Protein nitration results mainly from the reaction of aromatic amino acids with peroxynitrite, a strong oxidant formed by the reaction of nitric oxide ( $\mathrm{NO})$ and superoxide anion $\left(\mathrm{O}_{2}^{-\cdot}\right)$. In some inflammatory joint diseases, the reactive oxygen species " $\mathrm{NO}$ and $\left(\mathrm{O}_{2}^{-\cdot}\right)$ are produced by a large number of cells including macrophages and chondrocytes (Henrotin et al., 1993; Henrotin et al., 1998). Therefore, we have developed and validated two immunoassays allowing the measurement of Coll2-1 and Coll2-1NO $\mathrm{N}_{2}$ in human biological fluids. The first one recognized the amino acids sequence ${ }^{108}{ }^{\text {HRGYPGLDG }}{ }^{116}\left(\mathrm{Coll}_{2}-1\right)$ and the other recognized its nitrated form, ${ }^{108} \mathrm{HRGY}\left(\mathrm{NO}_{2}\right) \mathrm{PGLDG}^{116}\left(\mathrm{Coll} 2-1 \mathrm{NO}_{2}\right)$. Coll2-1 and Coll2-1 $\mathrm{NO}_{2}$ have been found to be elevated in sera of patients with knee OA as well as in patients with rheumatoid arthritis (Henrotin et al., 2004; Deberg et al., 2005). These markers were also measured in urines of a cohort of 75 patients with knee OA corresponding to the placebo arm of a large 3-year, randomized, double-blind study comparing the efficacy of glucosamine sulphate with placebo (Reginster et al., 2001). At baseline, significant correlations were found between the urinary levels of Coll2-1 and Coll2-1 $\mathrm{NO}_{2}$ and the Global Western Ontario Mc master Universities (WOMAC) algo-functional score. Furthermore, a negative correlation was observed between the first year change of these markers in urines, and the 3-year change of the medial joint space width, suggesting that the increase of these peptides over one year could be predictive of the radiological progression of knee OA (Deberg et al., 2003). Herein, we describe for the first time the measurement of these peptides in the plasma of horses. An homology of $100 \%$ of the sequence (HRGYPGLDG) exists between the human al chain of type II collagen and the equine al chain of type II collagen (Swiss Prot Database, accession number Q28396). We studied two groups of horses, a group suffering from osteochondral lesions and a control group. We categorised the horses into 3 classes following a clinical score according to the severity of symptoms, and following an inflammatory score and a degenerative score according to the lesions seen at arthroscopy. Our first hypothesis was that there should be a significant variation in the serum level of the 2 biomarkers, indicating the biomarker's ability to distinguish between pathological and healthy cases in the equine species. The second hypothesis was that a chronic inflammatory process might play a role in the pathophysiology of osteochondrosis that would lead to an increase of the nitrated collagen-fragment serum level in the pathological group. Our third hypothesis was that the mean marker levels should vary significantly between the horse classes, indicating the biomarker's ability to reflect the severity of the lesions. 


\section{Material and method}

\subsection{Animals}

The pathological group involved 34 horses of various breeds (mainly warmblood breeds of European countries), age (mean age $3.46 \pm 2.4$ years) and sex (19 males, 13 females, 2 geldings). The horses were presented to the large animal clinic of the Faculty of Veterinary Medicine at the University of Liège for either lameness investigation or veterinary examination for stallion admission to the Walloon Belgian warmblood studbook (sBs) between July 2002 and January 2004. All of them presented clinical symptoms (joint swelling, lameness, positive flexion test) and/or radiographic signs of osteochondral lesions. The affected articulations were metacarpo- or metatarsophalangeal joint (15 cases), tarsocrural joint ( 9 cases), femoropatellar joint ( 9 cases) and scapulohumeral joint ( 1 case). In 10 of the 34 horses bilateral joints were affected. Informed owner's consent was obtained before enrolling the horse in the study.

The control group included 37 horses of various breeds (mainly warmblood breeds and Ardennes light draught horses), age (mean age $3.52 \pm 2.2$ years) and sex (17 males, 18 females, 2 geldings). The horses were selected from the European Horse Centre at Mont le Soie and from 2 private stables and presented no clinical or radiographic signs of osteochondral lesions or other orthopaedic problems.

\subsection{Clinical examination and arthroscopy}

A complete physical lameness investigation was performed on all horses from the pathological group by one of the clinicians, using the same standard protocol. The horses underwent a radiographic examination including standard views of the fore and hind fetlocks, stifles and hocks in the case of the stallion admission examination. Views were taken of the localising joint and its opposite contralateral limb in the horses presented for lameness investigation. Horses of this last group were operated on by arthroscopy on the owner's request. The same surgeon carried out all arthroscopies with a 4-mm arthroscope ${ }^{2}$ with a $30^{\circ}$ fore oblique lens using standard arthroscopic technique as described previously (Nixon, 1987; McIlwraith, 1990a). Arthroscopies were recorded using a digitalised videocamera. ${ }^{3}$

\subsection{Clinical and arthroscopic scores}

The records of the lameness investigation and the videotapes of the arthroscopies were reviewed in order to attribute clinical, degenerative and inflammatory scores as follows:

Clinical score. The following 3 clinical symptoms were graded in all horses of the pathological group: degree of lameness: 0-absent, 1-mild or American Association of Equine Practitioner's (AAEP) grade 1, 2-moderate or AAEP grades 2 and 3, 3-severe or AAEP grade 4 and 5; degree of pain on flexion and degree of joint swelling: 0 -absent, 1-mild, 2-moderate or 3-severe. The sum of the 3 grades made up the clinical score (0-9).

Inflammatory score. The following 5 parameters of joint inflammation were evaluated on arthroscopy recordings: hyperaemia, petechiation, thickening and increase in villi density, formation of new types of villi and rice bodies, atrophy and flattening with fibrin and adhesion formation, and subsequently graded as 0 -absent, 1mild, 2-moderate, 3-severe and extensive (McIlwraith, 1990b). The sum of the 5 grades made up the inflammatory score (0-15).

Degenerative score. The cartilage damage was graded as follows: 0-normal, 1-swelling, softening, 2-superficial fibrillation, 3-deep fibrillation down to bone, 4-exposure of subchondral bone (Ayral et al., 1996). The extent of the lesions was graded as 1-small, localised to the fragment site, 2-focalised in area around fragment site or on other, separate sites, 3-on fragment site as well as on other sites, 4-extensive, including large parts of the articular surface. The sum of the damage grade and the extent grade made up the degenerative score (0-8).

The horses were grouped in 3 classes for each scoring system according to the obtained score (Table 1).

\footnotetext{
${ }^{2}$ Karl Storz Veterinary Endoscopy, Goleta, CA.

${ }^{3}$ Sony DCR-TRV890E, Sony Coorporation, Tokyo, Japan.
} 
Table 1 Clinical and arthroscopic (degenerative and inflammatory) scoring system

\begin{tabular}{lccccc}
\hline Clinical score & \multicolumn{3}{c}{ Degenerative score } & \multicolumn{3}{c}{ Inflammatory score } \\
\hline Parameters & Scores & Parameters & Scores & Parameters & Scores \\
\hline lameness & $0-3$ & Cartilage damage & $0-4$ & Hyperemia & $0-3$ \\
Joint swelling & $0-3$ & Extent of lesions & $0-4$ & Petechiation & $0-3$ \\
Flexion pain & $0-3$ & & & Villi thickening & $0-3$ \\
& & & & New villi types & $0-3$ \\
& & & Atrophy, adhesions & $0-3$ \\
Total score & $0-9$ & Total score & $0-8$ & Total score & $0-15$ \\
Class 1 & $0-3$ & Class 1 & $0-3$ & Class 1 & $0-4$ \\
Class 2 & $4-6$ & Class 2 & 4,5 & Class 2 & $5-8$ \\
Class 3 & $7-9$ & Class 3 & $6-8$ & Class 3 & $>8$ \\
\hline
\end{tabular}

\subsection{Samples}

Venous blood samples were obtained from the jugular veins and collected into tubes containing EDTA (1 mg/ $\mathrm{ml}$ ). They were centrifuged at $7000 \mathrm{~g}$ for $10 \mathrm{~min}$, the plasma was aliquoted and frozen at $-20{ }^{\circ} \mathrm{C}$ within $60 \mathrm{~min}$ from sampling. Plasma samples were not thawed until assayed.

\subsection{Coll2-1 and Coll2-1NO $\mathrm{N}_{2}$ immunoassays}

These assays are two competitive immunoassays described in details by Henrotin et al. (2004). Briefly, microplates were coated with $200 \mu \mathrm{l}$ of streptavidine $0.5 \mathrm{mg} / \mathrm{ml}$ during at least $48 \mathrm{~h}$. After washing (buffer washing: Tris $25 \mathrm{mM}, \mathrm{NaCl} 50 \mathrm{mM}$, Tween 20,0.2\% (v/v), pH 7.3), microtiter plates were subsequently blocked with $400 \mu \mathrm{l} /$ well of blocking buffer $\left(\mathrm{KH}_{2} \mathrm{PO}_{4} 1.5 \mathrm{mM}, \mathrm{Na}_{2} \mathrm{HPO}_{4} 8 \mathrm{mM}, \mathrm{KCl} 2 \mathrm{mM}, \mathrm{NaCl} 138 \mathrm{mM}, \mathrm{BSA} 0.5 \%\right.$ $(\mathrm{v} / \mathrm{v})$, monohydrate lactose $5.3 \mathrm{~g} / 100 \mathrm{ml}(\mathrm{w} / \mathrm{v}), \mathrm{pH} 7.2)$ for a night at $4{ }^{\circ} \mathrm{C}$. Coll2-1 and Coll2- $1 \mathrm{NO}_{2}$ were conjugated to biotin according to the method described by Rosenquist et al. (1998). After washing, $100 \mu 1$ of these biotinylated peptides either Coll2-1 at $2.5 \mathrm{ng} / \mathrm{ml}$ or Coll2-1 $\mathrm{NO}_{2}$ at $1.25 \mathrm{ng} / \mathrm{ml}$, were added to each well of streptavidine-coated plates and incubated for $2 \mathrm{~h}$ at room temperature. Fifty $\mu \mathrm{l}$ of calibrators (synthetic peptide) or unknown samples, diluted 8-fold in dilution buffer (10 mM phosphate buffer saline (PBS), $138 \mathrm{mM} \mathrm{NaCl}$, $0.7 \%(\mathrm{w} / \mathrm{v}) \mathrm{BSA}, 0.1 \%(\mathrm{v} / \mathrm{v})$ Tween 20, pH 7.0, for the Coll2-1 immunoassay and in $50 \mathrm{mM}$ Tris, $138 \mathrm{mM}$ $\mathrm{NaCl}, 0.7 \%$ (w/v) BSA, $0.1 \%$ (v/v) Tween 20, pH 8.0, for the Coll2-1 $\mathrm{NO}_{2}$ immunoassay), were applied to the wells, followed by either $100 \mu \mathrm{l}$ of D3 antibody, diluted 1/40,000 or $100 \mu 1$ of D37 antiobody, diluted 1/500,000, and incubated $1 \mathrm{~h}$ at room temperature. The dilutions of the antisera and of the secondary antibody were done in $10 \mathrm{mM}$ PBS, $138 \mathrm{mM} \mathrm{NaCl}, 0.2 \%$ (w/v) BSA, 0.1\% (v/v) Tween 20, pH 7.0, for the Coll2-1 immunoassay and in $50 \mathrm{mM}$ Tris, $138 \mathrm{mM} \mathrm{NaCl}, 0.2 \%$ (v/v) BSA, $0.1 \%$ (v/v) Tween 20, pH 8.0, for the Coll2-1 $\mathrm{NO}_{2}$ immunoassay. After washing, $100 \mu \mathrm{l}$ of peroxidase-conjugated goat antibodies to rabbit $\mathrm{IgG},{ }^{4}$ diluted $1 / 5000$, were incubated $1 \mathrm{~h}$ at room temperature. After washing, $100 \mu \mathrm{l}$ of freshly prepared enzyme substrate ${ }^{5}$ were $^{-}$ added into each well. After $15 \mathrm{~min}$, the reaction was stopped with $100 \mu \mathrm{l}$ of $4 \mathrm{M} \mathrm{H}_{3} \mathrm{PO}_{4}$. The coloration was read with a microplate reader ${ }^{6}$ at $450 \mathrm{~nm}$, corrected for absorbance at $650 \mathrm{~nm}$. Coll2-1 immunoassay did not recognize native type I and II collagens, denaturated type I and II collagens, and BSA. Coll2-1 $\mathrm{NO}_{2}$ immunoassay did not recognize nitrated type I and II collagen, nitrated BSA and the 3-nitro-L-tyrosine residue, but a low cross reactivity of $0.02 \%$ with Coll2-1 was observed. The limits of detection were $17 \mathrm{nM}$ and $50 \mathrm{pM}$ for Coll2-1 and Coll2- $1 \mathrm{NO}_{2}$ immunoassays, respectively. For both immunoassays, the coefficients of variation were below $10 \%$. To avoid a matrix effect, the plasma samples should be diluted at least 8 -fold. The spiking recovery ranged from $101.8 \%$ to $106.5 \%$ for Coll2-1 and from $106.2 \%$ to $132.2 \%$ for Coll2-1 $\mathrm{NO}_{2}$ immunoassays, respectively.

\subsection{Statistical analyses}

All data was analysed using a commercial software program. ${ }^{7}$ If tests (Kolmogorov-Smirnov test) showed significant deviation from Gaussian distribution, medians were compared using non-parametric tests (MannWhitney test and Kruskal-Wallis test), otherwise means were compared using $t$ tests. Correlation coefficients between the clinical and arthroscopic scores were established using the non-parametric Spearman's rank

\footnotetext{
${ }^{4}$ Sigma-Aldrich, Bornem, Belgium.

${ }^{5}$ Biosource Europe S.A., Nivelles, Belgium.

${ }^{6}$ Labsystem iEMS Reader MF, Helsinki, Finland.

7 GraphPad InStat Version 3.06, GraphPad Software, San Diego, CA.
} 
correlation. For all tests, a $P$-value $<0.05$ was considered significant. Graphs were constructed using commercial graphic software. ${ }^{8}$

\section{Results}

\subsection{Coll2-1 and Coll2-1NO 2 concentrations}

There was no significant difference between the mean ages of the control group $(3.52 \pm 2.2$ years $)$ and the pathological group $(3.46 \pm 2.4$ years $)(P=0.397)$.

The median value of the Coll2-1 marker measurements was significantly higher $(P<0.0001)$ in the control group (1009.7 nM, minimum $366.6 \mathrm{nM}$, maximum $1534.5 \mathrm{nM}$ ) than in the pathological group (580.1 nM, minimum $419.2 \mathrm{nM}$, maximum $952.2 \mathrm{nM}$ ) (Fig. 1a). On the other hand, the median value of the nitrated peptide $\left(\right.$ Coll2-1 $\left.\mathrm{NO}_{2}\right)$ measurements showed a 2.8 -fold elevation $(P<0.0001)$ in the pathological group $(5.06 \mathrm{nM}$, minimum $0.18 \mathrm{nM}$, maximum $8.20 \mathrm{nM})$ as compared to the control group $(1.81 \mathrm{nM}$, minimum $0.87 \mathrm{nM}$, maximum $4.05 \mathrm{nM}$ ) (Fig. 1b).

Fig. 1. (a) Coll2-1 measurements in horses $(n=37)$ of the control group and in horses $(n=34)$ of the pathological group. A highly significant variation of the medians was found $(P<0.0001)$. (b) Coll2-1NO $\mathrm{N}_{2}$ measurements in horses $(n=37)$ of the control group and in horses $(n=34)$ of the pathological group. A highly significant variation of the medians was found $(P<0.0001)$.
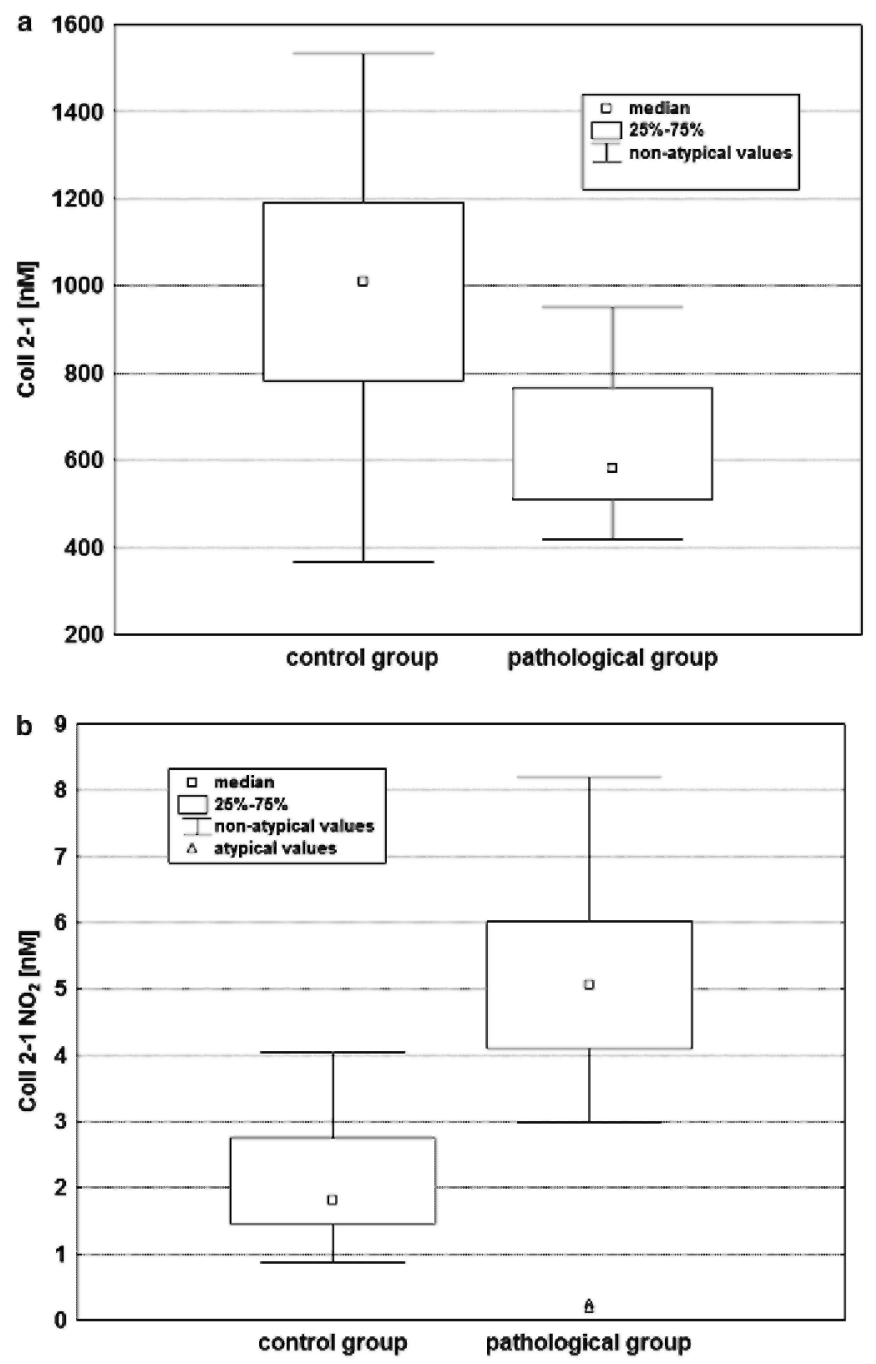

\footnotetext{
${ }^{8}$ Stat Soft France (2003), Statistica (logiciel d'analyse de données), version 6.
} 


\subsection{Clinical and arthroscopic scores}

The experimental population was stratified according the clinical score. Fifteen horses were included in class 1 , 15 in class 2 and 4 in class 3. Of these 34 horses, 16 underwent arthroscopy at request of owners. If bilateral articulations were affected, both were scored and the horse classified according to the higher score. For the degenerative score, 4 horses were included in class 1,8 in class 2 and 4 in class 3, for the inflammatory score 9 horses were included in class 1, 3 in class 2 and 4 in class 3 (Table 2).

The values of the clinical score correlated significantly with the values of the inflammatory score $(r=0.69, P=$ $0.003)$, but there was no significant correlation between the clinical score and the degenerative score $(r=0.34, P$ $=0.19)$, and the inflammatory score and the degenerative score $(r=0.23, P=0.40)$. When evaluating the medians of Coll2-1 and Coll 2-1 $\mathrm{NO}_{2}$ obtained for the 3 classes in each score, there were no significant variations (Table 2).

Table 2 Distribution of the 34 horses of the pathological group between the 3 classes for the scores and the median (minimum; maximum) Coll2-1 and Coll2-1NO $\mathrm{N}_{2}$ values [nM]

\begin{tabular}{lccc}
\hline Score & Class 1 & Class 2 & Class 3 \\
\hline Clinical score & & & 4 \\
Horses $(n)$ & 15 & 15 & 4 \\
Coll2-1 $[\mathrm{nM}]$ & $575.62(448.58 ; 952.24)$ & $576.90(428.24 ; 935.34)$ & $628.29(419.23 ; 741.89)$ \\
Coll2-1 $\mathrm{NO}_{2}[\mathrm{nM}]$ & $4.95(2.98 ; 7.50)$ & $5.15(0.18 ; 8.17)$ & $4.54(0.25 ; 6.75)$ \\
Degenerative score & & & 4 \\
Horses $(n)$ & 4 & 8 & $754.53(457.61 ; 784.81)$ \\
Coll2-1 $[\mathrm{nM}]$ & $693.22(576.90 ; 880.12)$ & $636.86(428.24 ; 935.34)$ & $5.76(0.18 ; 8.20)$ \\
Coll2-1 $\mathrm{NO}_{2}[\mathrm{nM}]$ & $4.16(3.06 ; 6.09)$ & $5.21(3.50 ; 6.88)$ & 4 \\
Inflammatory score & & & 3 \\
Horses $(n)$ & 9 & $767.16(665.23 ; 935.34)$ & $763.35(563.85 ; 880.12)$ \\
Coll2-1 $[\mathrm{nM}]$ & $611.96(428.24 ; 852.23)$ & $3.96(3.50 ; 8.20)$ & $5.76(3.85 ; 6.73)$ \\
Coll2-1 $\mathrm{NO}_{2}[\mathrm{nM}]$ & $4.98(0.18 ; 6.88)$ & &
\end{tabular}

Parameter grading for each score and class determination according to the total score.

\section{Discussion}

Herein, we have investigated the variation of two original biomarkers of type II collagen degradation in horses with osteochondral lesions (OC). Indeed, we found a highly significant difference between the medians in the control group and the pathological group for the 2 markers, confirming our first hypothesis. Coll2-1 is decreased in OC plasma, whereas Coll2-1 $\mathrm{NO}_{2}$ is increased, indicating an uncoupling variation of these two markers. This profile is different to that observed in primary osteoarthritis in humans where Coll2-1 and Coll2-1 $\mathrm{NO}_{2}$ are found to be elevated compared to healthy age-matched subjects (Henrotin et al., 2004). These findings indicate that Coll2-1 and Coll2- $1 \mathrm{NO}_{2}$ levels in blood are differently modulated in primary osteoarthritis in humans and in osteoarthritis secondary to OC in horse. This discrepancy can be explained by the difference in the pathological process.

The observation that the plasma level of Coll2-1 was lower in the OC group was surprising as it might indicate less type II-collagen breakdown in the cartilage from this group. This result seems also in conflict with earlier studies of equine osteochondrosis using other markers of type II-collagen breakdown, which showed an increase in situ in cartilage explants (Laverty et al., 2002), or a positive correlation with the severity of osteochondrotic lesions at 5 months age (Billingshurst et al., 2004). However these 2 studies used immature horses (12 months and less), whereas in our study the mean age of the horses with osteochondral lesions was $3.46 \pm 2.4$ years. Several studies demonstrated that osteochondrotic lesions developed at a very young age (Shingleton et al., 1997; Dik et al., 1999), so we can hypothesise that the horses we studied had reached a chronic stage of lesions with secondary degenerative changes. This was clearly reflected by the degenerative score established at arthroscopy: none of the joints had a score of 0 . In these chronic stages, most of the cartilage breakdown might 
already have been completed, resulting in a slowing down of collagen degradation. Interestingly, in the study of Billingshurst et al. (2004), a loss of correlation with the lesions at 11 months of age was observed for the type IIcollagen-specific marker of degradation, and a negative correlation was found for types I and II-collagen-specific marker of degradation, in contrast to the findings at 5 months of age, as mentioned earlier. This indicates a slowing down of the pathological process even before the age of one year, and could therefore corroborate our results in older animals. On the other hand, studies of endochondral ossification in bovine foetal physeal cartilage have shown an increased degradation of type II-collagen during physiological remodelling (Mwale et al., 2002; Wu et al., 2002). Therefore, disturbance of the normal process of enchondral ossification and physiological remodelling could also include a decrease in type II-collagen degradation. More studies on the molecular events of osteochondrosis using biomarker-technology are needed to further elucidate its pathophysiology. The lower plasma level of Coll2-1 in the OC-group might also be due to a higher excretion rate or due to an increased retention in matrix. Although these possibilities seem less likely, measurements of urine marker levels as well as in situ measurements using immunohistochemical techniques would be interesting in order to exclude them as potential pathogenic mechanisms.

Our second hypothesis that the nitrated marker should be increased in the horses with osteochondral lesions was equally confirmed. This result could provide evidence of an increased extracellular matrix protein nitration in equine osteochondral lesions, since until recently, nitrotyrosine $\left(\mathrm{NO}_{(2)} \mathrm{Tyr}\right)$ formation has been considered to be a specific marker for protein oxidation by peroxynitrite $\left(\mathrm{ONOO}^{-}\right)$, an unstable oxidant formed during neardiffusion limited interaction of superoxide $\left(\mathrm{O}_{2}^{-}\right)$and nitric oxide 'NO) (Baldus et al., 2002; Brennan et al., 2002). Superoxide anion and nitric oxide productions in chondrocyte and in synovial cultures have been widely demonstrated (Stichtenoth and Frölich, 1998; Henrotin et al., 2003). However, in recent years other pathways of nitrotyrosine-formation have been suggested. The most frequently discussed alternative mechanism involves myeloperoxidase (MPO)-catalysed tyrosine nitration (Baldus et al., 2002; Brennan et al., 2002; Gaut et al., 2002). Due to the instability of nitric oxide and peroxynitrite, the former pathway of nitrotyrosine formation must take place near their production site, in our case in the articulation, as the horses did not suffer from an acute or chronic inflammation elsewhere. MPO is a specific enzyme of polymorphonuclear leucocytes (PMN) and is released when these cells are stimulated during inflammatory reactions. Increased MPO activity was observed in antigen-induced arthritis in guinea pigs and was attributed to neutrophils attracted to synovial tissue (Kuwabara et al., 2002). It has recently been reported that MPO mRNA levels are increased in osteoarthritic chondrocytes (Attur et al., 2002).

In our study, the nitrated peptide marker was measured in the plasma. Therefore the tyrosine-residue could have been nitrated either in the articulation (either in the cartilage matrix, in the synovial fluid or the synovial membrane), or in the plasma. In order to explore where and through which pathway the tyrosine-residue was nitrated, measurements of the Coll2-1 and the Coll2- $1 \mathrm{NO}_{2}$ marker levels in synovial fluid would be interesting, as well as concomitant measurement of MPO-level in plasma and synovial fluid.

Our last hypothesis, that there should be a significant variation of the marker medians in the 3 classes of the established inflammatory score, degenerative score and clinical score, was not confirmed. However, the medians of Coll2-1 and Coll2-1 showed a general tendency with some exceptions to increase with increasing class number and therefore severity of the lesions. Significance might not have been reached because the sample was too small ( $n=16$ horses), and it would be interesting to repeat the study on a larger cohort of animals. On the other hand, it is possible that serum measurements might reflect systemic changes in collagen turnover rather than local pathological changes in the signal joint (Lohmander, 1997; Poole, 2003). Therefore the markers might not correlate well with the degree of lesions observed because they might not reflect joint disease, but rather differences in metabolism that put some horses more at risk of developing osteochondral lesions than others. This point of view warrants further investigation, as endocrine dysfunction and nutritional influences have already been put forward as possible factors in the pathogenesis of osteochondral lesions. Note that the scoring system we used has not yet been validated. The fact that there's a significant correlation between the clinical score and the inflammatory score, but not with the degenerative score, might indicate that the joint inflammation is at the origin of the symptoms rather than the cartilage degradation. Unlike in human arthroscopy, to our knowledge, no validated scoring system exists to date in equine arthroscopy (Ayral et al., 1996). However, such a validated grading system is absolutely necessary in order to quantify joint damage and test a marker's ability to reflect the degree of joint damage.

In conclusion, the data reported herein suggests that the 2 ELISAs using the biomarkers Coll2-1 and $\mathrm{Coll}_{2}-1 \mathrm{NO}_{2}$ are able to reflect alterations in cartilage matrix turnover in horses suffering from osteochondral lesions. It still needs to be established whether the markers are also able to differentiate other joint pathologies. The marker Coll2 $-1 \mathrm{NO}_{2}$ clearly demonstrated an increase of collagen fragment nitration and therefore implicated an 
inflammatory phenomenon in the pathophysiology of osteochondral lesions and secondary degenerative changes. As mentioned above, further studies are needed to elucidate the site and origin of nitration of the marker. To our knowledge this is the first marker described which reflects at the same time both collagen breakdown and inflammation, and would therefore be a very interesting tool to study the pathophysiology of various equine joint diseases.

The scoring system we propose needs to be validated. Furthermore, not only cross-sectional but also longitudinal studies would be of great interest in order to assess the marker's ability to be of prognostic value or to monitor response to various management and treatment protocols.

\section{References}

Attur, M.G., Dave, M., Akamatsu, M., Katoh, M., Amin, A.R., 2002. Osteoarthritis or osteoarthrosis: the definition of inflammation becomes a semantic issue in the genomic era of molecular medicine. Osteoarthritis Cartilage 10, 1-4.

Ayral, X., Dougados, M., Listrat, V., Bonvarlet, J.-P., Simonnet, J., Amor, B., 1996. Arthroscopic evaluation of chondropathy in osteoarthritis of the knee. Journal of Rheumatology 23, 698-706.

Baldus, S., Eiserich, J.P., Brennan, M.-L., Jackson, R.M., Alexander, C.B., Freeman, B.A., 2002. Spatial mapping of pulmonary and vascular nitrotyrosine reveals the pivotal role of myeloperoxidase as a catalyst for tyrosine nitration in inflammatory diseases. Free Radical Biology \& Medicine 33, 1010-1019.

Billingshurst, R.C., Buxton, E.M., Edwards, M.G., McGraw, M.S., McIlwraith, C.W., 2001. Use of an antineoepitope antibody for identification of type-II collagen degradation in equine articular cartilage. American Journal of Veterinary Research 62, $1031-1039$.

Billingshurst, R.C., Brama, P.A.J., Van Weeren, P.R., Knowlton, M.S., McIlwraith, C.W., 2003. Significant exercise-related changes in the serum levels of two biomarkers of collagen metabolism in young horses. Osteoarthritis Cartilage 11, 760-769.

Billingshurst, R.C., Brama, P.A.J., Van Weeren, P.R., Knowlton, M.S., McIlwraith, C.W., 2004. Evaluation of serum concentrations of biomarkers of skeletal metabolism and results of radiography as indicators of severity of osteochondrosis in foals. American Journal of Veterinary Research 65, 143-150.

Brennan, M.-L., Wu, W., Fu, X., Shen, Z., Song, W., Frost, H., Vadseth, C, Narine, L., Lenkiewicz, E., Borchers, M.T., Lusis, A.J., Hazen, S.L., 2002. A tale of two controversies. Defining both the role of peroxidases in nitrotyrosine formation in vivo using eosinophil peroxidase and myeloperoxidase-deficient mice, and the nature of peroxidase-generated reactive nitrogen species. Journal of Biological Chemistry 277 , $17415-17427$.

Bridges, C.H., Harris, E.D., 1988. Experimentally induced cartilaginous fractures (osteochondrosis dissecans) in foals fed low-copper diets. Journal of The American Veterinary Medical Association 193, 215-221.

Caron, J.P., 2003. Osteoarthritis. In: Ross, M.W., Dyson, S.J. (Eds.), Diagnosis and Management of Lameness in the Horse, first ed. WB Saunders Co, Philadelphia, pp. 572-591

Deberg, M., Labasse, A., Christgau, S., Henriksen, D., Reginster, J.Y., Henrotin, Y.E., 2003. Cartilage degradation and oxidative damage in osteoarthritic and rheumatoid arthritic patients. Osteoarthritis Cartilage 11, 36.

Deberg, M., Labasse, A., Christgau, S., Cloos, P., Henriksen, D., Chapelle, J.P., Zegels, B., Reginster, J.Y., Henrotin, Y., 2005. New serum biochemical markers (Coll2-1 and Coll2- $1 \mathrm{NO}_{2}$ ) for studying oxidative-related type II collagen network degradation in patients with osteoarthritis and rheumatoid arthritis. Osteoarthritis Cartilage 13, 258-265.

Dik, K.J., Enzerink, E., Van Weeren, P.R., 1999. Radiographic development of osteochondral abnormalities, in the hock and stifle of Dutch warmblood foals, from age 1 to 11 months. Equine Veterinary Journal Supplement 31, 9-15.

Dimock, A.N., Siciliano, P.D., McIlwraith, C.W., 2000. Evidence supporting an increased presence of reactive oxygen species in the diseased equine joint. Equine Veterinary Journal 32, 439-443.

Douglas, J., 2003. Pathogenesis of osteochondrosis. In: Ross, M.W., Dyson, S.J. (Eds.), Diagnosis and Management of Lameness in the Horse, first ed. WB Saunders Co, Philadelphia, pp. 534-543.

Frisbie, D.D., Al-Sobayil, F., Billingshurst, R.C., McIlwraith, C.W., 2002. Serum Biomakers distinguish exercise from osteoarthritic pathology. Osteoarthritis Cartilage Supplement 10, S53.

Garnero, P., Rousseau, J.-C., Delmas, P.D., 2000. Molecular basis and clinical use of biochemical markers of bone, cartilage, and synovium in joint diseases. Arthritis Rheumatism 43, 953-968. 
Gaut, J.P., Byun, J., Tran, H.D., Lauber, W.M., Carroll, J.A., Hotchkiss, R.S., Belaaouaj, A., Heinecke, J.W., 2002. Myeloperoxidase produces nitrating oxidants in vivo. Journal of Clinical Investigation 109, 1311-1319.

Henrotin, Y.E., Deby-Dupont, G.P., Deby, C, De Bruyn, M., Lamy, M., Franchimont, P., 1993. Production of active oxygen species by isolated human chondrocytes. British Journal of Rheumatology 32, 562-567.

Henrotin, Y.E., Zheng, S.X., Deby-Dupont, G.P., Labasse, A., Crielaard, J.M., Reginster, J.Y., 1998. Nitric oxide downregulates interleukin $1 \beta$ (IL-1 $\beta$ ) stimulated IL-6, IL-8, and prostaglandin $\mathrm{E}_{2}$ production by human chondrocytes. Journal of Rheumatology $25,1595-1601$.

Henrotin, Y.E., Bruckner, P., Pujol, J.P.L., 2003. The role of active oxygen species in homeostasis and degradation of cartilage. Osteoarthritis Cartilage 11, 747-755.

Henrotin, Y.E., Deberg, M., Dubuc, J.E., Quettier, E., Christgau, S., Reginster, J.Y., 2004. Type II collagen peptides for measuring cartilage degradation. Biorheology 41, 543-547.

Henson, F.M.D., Davies, M.E., Schofield, P.N., Jeffcott, L.B., 1996. Expression of types II, VI and X collagen in equine growth cartilage during development. Equine Veterinary Journal 28, 189-198.

Hurtig, M., Green, S.L., Dobson, H., Mikuni-Takagaki, Y., Choi, J., 1993. Correlative study of defective cartilage and bone growth in foals fed a low-copper diet. Equine Veterinary Journal Supplement 16, 66-73.

Jeffcott, L.B., 1991. Osteochondrosis in the horse-searching for the key to pathogenesis. Equine Veterinary Journal 23, 331-338.

Jeffcott, L.B., Henson, F.M.D., 1998. Studies on growth cartilage in the horse and their application to aetiopathogenesis of dyschondroplasia (Osteochondrosis). Veterinary Journal 156, 177-192.

Kuwabara, K., Jyoyama, H., Fleisch, J.H., Hori, Y., 2002. Inhibition of antigen-induced arthritis in guinea-pigs by a selective LTB receptor $^{2}$ antagonist LY293111Na. Inflammation Research 51, 541-550.

Laverty, S., O'Kouneff, S., Ionescu, M., Reiner, A., Pidoux, I., Webber, C, Rossier, Y., Billingshurst, R.C., Poole, A.R., 2002. Excessive degradation of type II collagen in articular cartilage in equine osteochondrosis. Journal of Orthopaedic Research 20, $1282-1289$.

Lillich, J.D., Bertone, A.L., Malemud, C.J., Weisbrode, S.E., Ruggles, A.J., Stevenson, S., 1997. Biochemical, histochemical and immunohistochemical characterization of distal tibial osteochondrosis in horses. American Journal of Veterinary Research 58, 89-98.

Lohmander, L.S., 1997. What is the current status of biochemical markers in the diagnosis, prognosis and monitoring of osteoarthritis? Baillière's Clinical Rheumatology 11, 711-726.

McIlwraith, C.W., 1990a. Diagnostic and surgical arthroscopy of the metacarpophalangeal and metatarsophalangeal joints, of the femoropatellar and femorotibial joints, of the tarsocrural joint. In: McIlwraith, C.W. (Ed.), Diagnostic and Surgical Arthroscopy of the Horse, second ed. Lea \& Febiger, Philadelphia, pp. 85-193.

McIlwraith, C.W., 1990b. General technique and diagnostic arthroscopy, evaluation of synovial membrane and synovitis. In: McIlwraith, C.W. (Ed.), Diagnostic and Surgical Arthroscopy of the Horse, second ed. Lea \& Febiger, Philadelphia, pp. 27-30.

Mwale, F., Tchetina, E.V., Wu, C.W., Poole, A.R., 2002. The assembly and remodeling of the extracellular matrix in the growth plate in relationship to mineral deposition and cellular hypertrophy: an in situ study of collagens II and IX and proteoglycan. Journal of Bone and Mineral Research 17, 275-283.

Nixon, A.J., 1987. Diagnostic and surgical arthroscopy of the equine shoulder joint. Veterinary Surgery 16, 44-52.

Poole, A.R., 2003. Biochemical/immunochemical biomarkers of osteoarthritis: utility for prediction of incident or progressive osteoarthritis. Rheumatic Disease Clinics of North America 29, 803-818.

Reginster, J.Y., Deroisy, R., Rovati, L.C., Lee, R.L., Lejeune, E., Bruyere, O., Giacovelli, G., Henrotin, Y., Dacre, J.E., Gossett, C, 2001. Long-term effects of glucosamine sulphate on osteoarthritis progression: a randomised, placebo-controlled clinical trial. The Lancet 357, 251-256.

Rosenquist, C., Fledelius, C., Christgau, S., Pedersen, B.J., Bonde, M., Qvist, P., Christiansen, C., 1998. Serum CrossLaps one step ELISA. First application of monoclonal antibodies for measurement in serum of bone-related degradation products from C-terminal telopeptides of type I collagen. Clinical Chemistry 44, 2281-2289.

Schiller, J., Fuchs, B., Arnhold, J., Arnold, K., 2003. Contribution of active oxygen species to cartilage degradation in rheumatic diseases: molecular pathways, diagnosis and potential therapeutic strategies. Current Medicinal Chemistry 10, 2123-2145.

Shingleton, W.D., Mackie, E.J., Cawston, T.E., Jeffcott, L.B., 1997. Cartilage canals in equine articular/epiphyseal growth cartilage and a possible association with dyschondroplasia. Equine Veterinary Journal 29, 360-364. 
Published in : Research in Veterinary Science (2007), vol. 82, pp. 68-75.

Status : Postprint (Author's version)

Stichtenoth, D.O., Frölich, J.C., 1998. Nitric oxide and inflammatory joint diseases. British Journal of Rheumatology 37, $246-257$.

Todhunter, R.J., Lust, G., 1990. Pathophysiology of Synovitis: clinical signs and examination in horses. Compendium on Continuing Education for the Practicing Veterinarian 12, 980-992.

Van den Hoogen, B.M., Van de Lest, C.H.A., Van Weeren, P.R., Van Golde, L.M.G., Barneveld, A., 1999. Changes in proteoglycan metabolism in osteochondrotic articular cartilage of growing foals. Equine Veterinary Journal Supplement 31, 38-44.

Von Rechenberg, B., McIlwraith, C.W., Akens, M.K., Frisbie, D.D., Leutenegger, C, Auer, J.A., 2000. Spontaneous production of nitric oxide (NO), prostaglandin ( $\mathrm{PGE}_{2}$ ) and neutral metalloproteinases (NMPs) in media of explant cultures of equine synovial membrane and articular cartilage from normal and osteoarthritic joints. Equine Veterinary Journal 32, 140-150.

Wu, C.W., Tchetina, E.V., Mwale, F., Poole, A.R., 2002. Proteolysis involving matrix metalloproteinase 13 (collagenase-3) is required for chondrocyte differentiation that is associated with matrix mineralization. Journal of Bone and Mineral Research 17, 639-651. 